\title{
ID1 upregulation and FoxO3a downregulation by Epstein- Barr virus-encoded LMP1 in Hodgkin's lymphoma
}

\author{
JUN-ICHIRO IKEDA, NAOKI WADA, SATOSHI NOJIMA, SHINICHIRO TAHARA, \\ YOKO TSURUTA, KAORI OYA and EIICHI MORII
}

Department of Pathology, Osaka University Graduate School of Medicine, Suita, Osaka 565-0871, Japan

Received April 6, 2016; Accepted July 25, 2016

DOI: $10.3892 /$ mco.2016.1012

\begin{abstract}
Cancer-initiating cells (CICs) are specialized cells that have the ability to self-renew and are multipotent. We recently demonstrated that Forkhead box O3a (FoxO3a)-expressing cells exhibited a CIC-like potential in Hodgkin's lymphoma (HL). A proportion of HL patients are infected with Epstein-Barr virus (EBV). EBV-encoded latent membrane protein (LMP) 1 downregulates FoxO3a, suggesting that FoxO3a expression may be abolished in EBV-positive HL. Inhibitors of DNA-binding (ID) proteins are highly conserved transcription factors mediating stem cell functions. To the best of our knowledge, no study has investigated possible associations among ID1, FoxO3a and LMP1 expression in HL to date. We immunohistochemically evaluated the expression of the three abovementioned factors in HL patients. The ID1 expression level was inversely correlated with that of FoxO3a $(\mathrm{P}=0.00035)$. LMP1-positive HL cells abundantly expressed ID1 $(\mathrm{P}=0.029)$, but not FoxO3a $(\mathrm{P}=0.00085)$. Thus, our previous observation that FoxO3a may serve as a marker of CICs may not be applicable in EBV-positive HL patients, but rather ID1 may be a candidate CIC marker in this type of HL.
\end{abstract}

\section{Introduction}

Tumor cells with tumorigenic potential constitute small populations, referred to as cancer-initiating cells (CICs), which have the ability to self-renew and are multipotent. CICs are found in a number of tumors (1-12). As CICs efficiently eliminate antitumor chemicals, are resistant to radiotherapy and degrade reactive oxygen species (ROS), they are considered to cause cancer recurrence and/or metastasis (13-16).

Correspondence to: Professor Eiichi Morii, Department of Pathology, Osaka University Graduate School of Medicine, Yamada-oka 2-2, Suita, Osaka 565-0871, Japan

E-mail: morii@molpath.med.osaka-u.ac.jp

Key words: inhibitor of DNA-binding protein 1, Forkhead box O3a, latent membrane protein 1, cancer-initiating cells, Hodgkin's lymphoma
Hodgkin's lymphoma (HL) is a monoclonal lymphoid neoplasm diagnosed by the presence of multinucleated (Reed-Sternberg; RS) cells admixed with singly nucleated Hodgkin cells (tumor cells) and various inflammatory cells. Although the cellular origin of HL remains controversial, recent molecular biological studies have revealed that $\mathrm{HL}$ is principally a B-cell neoplasm $(17,18)$. The CICs of HL have not been extensively investigated. Jones et al, in a study on HL patients, described a small circulating clonotypic B-cell population expressing high levels of aldehyde dehydrogenase and CD27; these cells efficiently formed colonies in vitro (19). Nakashima et al investigated 'side populations' (SPs), which were negative for CD133 and CD44, but exhibited the characteristics of CICs, in several tumors. The SPs consisted of small mononuclear cells and those of HL were resistant to chemotherapeutic agents (20). We recently demonstrated that intracellular ROS levels were lower in a proportion of singly nucleated HL cells compared with those in the RS cells of HL. The ROS-low cells exhibited anti-apoptotic and tumorigenic potential, similar to CICs, and abundantly expressed Forkhead box $\mathrm{O} 3 \mathrm{a}$ (FoxO3a), a transcription factor regulating the expression of genes encoding ROS-degrading enzymes. These results suggested that these FoxO3a-expressing cells may constitute the CICs of $\mathrm{HL}(3,21,22)$.

Inhibitor of DNA-binding (ID) proteins constitute a family of highly conserved transcriptional regulators that play pivotal roles during development and in the maintenance of adult tissue homeostasis. The major biological effects of ID proteins are inhibition of differentiation and maintenance of the self-renewal ability and multipotency of stem cells (23). ID proteins are overexpressed in a number of human cancers; deregulation of ID protein expression is directly involved in cancer initiation, maintenance, progression and development of drug resistance (characteristics of CICs). ID1 transcription is negatively regulated by FoxO3a in leukemic cells (24). In nasopharyngeal carcinoma, Epstein-Barr virus (EBV)-encoded latent membrane protein (LMP) 1 phosphorylates and inactivates FoxO3a, thereby upregulating ID1 (25-27). These results suggest that the pathogenetic progression of certain tumors may be controlled by these three factors, namely ID1, FoxO3a and LMP1. EBV has been hypothesized to play a role in the pathogenesis of HL, and EBV-positive HL tissue expresses LMP1. To the best of our knowledge, no study has yet investigated the associations 
among ID1, FoxO3a and LMP1 in HL. The aim of the present study was to address this topic.

\section{Materials and methods}

Patients. This study received ethical approval from the Institutional Review Board of Osaka University (12467-2). From 1999 to 2015, informed consent was obtained from 31 HL patients who were included in this study. Formalin-fixed paraffin-embedded (FFPE) diagnostic samples were stored in the dark room of the Department of Pathology of Osaka University Hospital at room temperature, and $4-\mu \mathrm{m}$ sections were obtained prior to staining with hematoxylin and eosin, followed by routine immunohistochemical evaluation.

Immunohistochemical analysis of FoxO3a, IDI and LMPI expression. Anti-FoxO3a (rabbit monoclonal, cat. no. 12,829, Cell Signaling Technology Inc., Beverly, MA, USA), anti-ID1 (rabbit monoclonal, ab134163, Abcam Ltd., Cambridge, UK) and anti-LMP1 (mouse monoclonal, cat. no. M0897, Dako A/S, Glostrup, Denmark) antibodies were used for immunohistochemical analysis. Antigen retrieval was performed with the aid of a Pascal pressurized heating chamber (Dako). The sections were incubated with anti-FoxO3a (100-fold dilution), anti-ID1 (200-fold dilution) and anti-LMP1 (100-fold dilution) antibodies, and color was developed with the aid of the ChemMate EnVision kit (Dako). Diaminobenzidine (DAB) (Dako) served as the chromogen. The negative controls underwent all the abovementioned steps, except for incubation with the primary antibodies. The intensity of immunohistochemical staining was categorized as none, weak to moderate, and strong. Weak to moderate and strong were considered as positive signals. When signals from FoxO3a and ID1 were detected in $>1 \%$ of Hodgkin and RS cells, that case was adjudged positive, as CICs constitute a minority of tumor cells. In addition to tumor cells, some non-tumor cells, such as inflammatory cells, macrophages and vascular endothelial cells, were also positive for FoxO3a and ID1, which were considered to be positive controls $(3,28)$. When LMP1 expression was detected in $>20 \%$ of tumor cells, that case was adjudged as positive (EBV-positive criterion) (29). All staining data were independently evaluated by two pathologists (J. I. and E.M.) and the evaluation results were matched.

In situ hybridization (ISH). ISH using an EBV-encoded small RNA (EBER) probe was performed to determine whether the EBV genome was present in the FFPE sections; the EBER DAB application kit (Dako) was used. Briefly, the sections were treated with proteinase $\mathrm{K}$ diluted 1:10 in TBS $(50 \mathrm{mmol} / \mathrm{l}$ Tris- $\mathrm{HCl}$ buffered saline containing $150 \mathrm{mmol} / \mathrm{l} \mathrm{NaCl}$; $\mathrm{pH}$ 7.6) and then hybridized with the EBER peptide nucleic acid probe tagged with fluorescein (Dako) at $55^{\circ} \mathrm{C}$ for $90 \mathrm{~min}$. After blocking endogenous peroxidase activity, the sections were incubated with rabbit anti-fluorescein isothiocyanate antibody (dilution 1:50; rabbit polyclonal, cat. no. 71-1900, Invitrogen, Carlsbad, CA, USA) at room temperature for $30 \mathrm{~min}$, followed by incubation with the ChemMate ENVISION/HRP polymer (Dako) at room temperature for $30 \mathrm{~min}$. DAB was used for color development. As previously suggested, when signal from EBER was evident in $>20 \%$ of tumor cells, that case was adjudged as EBV-positive (30). All staining data were independently evaluated by two pathologists (J.I. and E.M.).

Statistical analysis. Statistical analyses were performed with the aid of JMP software (SAS Institute Inc., Cary, NC, USA). The Chi-square and Fisher's exact probability tests were used to assess the correlations among three groups, namely those expressing ID1, FoxO3a and LMP1 among HL cells. A P-value of $<0.05$ was considered to reflect statistical significance.

\section{Results}

Histological subtypes of HL. A total of 31 patients diagnosed with HL were investigated following approval of the study protocol by the Institutional Review Board of Osaka University Hospital. The histological subtypes were classified as 15 mixed-cellularity classical HL (MCCHL), 13 nodular sclerosis classical HL (NSCHL), 1 lymphocyte-rich classical HL (LRCHL) and 2 nodular lymphocyte-predominant HL (NLPHL).

Immunohistochemistry for IDI and FoxO3a. To determine the association between ID1 and FoxO3a expression, ID1 and FoxO3a were immunohistochemically detected. Tumor cells stained for ID1 (strong cytoplasmic staining) and FoxO3a (strong nuclear staining) (Fig. 1A-D). Of the 31 cases, 10 were ID1- and 20 FoxO3a-positive (Table I). The ID1 expression level was inversely correlated with that of FoxO3a (Table II; $\mathrm{P}=0.00035$ ).

ISH for the detection of EBER-1 and immunohistochemistry for $L M P 1$. EBER-1 ISH was performed to determine whether the HL cases were infected with EBV (Fig. 1E-H). Thirteen of the 31 cases were EBV-positive, and all were also LMP1-positive, indicating that the EBV latent gene expression pattern was of type II (Table I). By histological subtype, 10 of 15 MCCHL (66.7\%), 1 of 13 NSCHL (7.7\%), 1 of 1 LRCHL (100\%) and 1 of 2 NLPHL (50\%) patients had EBER-1- and LMP1-positive tumor cells. The EBV-positive rates were consistent with those of previous studies, particularly in MCCHL and NSCHL (29).

Correlation between the expression of LMPI and IDI, and that of LMPI and FoxO3a. To compare the expression of LMP1 with that of ID1 and FoxO3a, our data were subjected to Chi-square testing. The expressions of LMP1 and ID1 were significantly associated (Table III; $\mathrm{P}=0.029$ ), but LMP1 and FoxO3a were not (Table III; $\mathrm{P}=0.00085$ ).

\section{Discussion}

The ID protein family contains four members; the ID proteins maintain the self-renewal potential and multipotency of stem cells. Overexpression of ID proteins has been reported in a number of tumors, and such deregulation is associated with tumor initiation and drug resistance (23,31). ID1 expression was found to be an independent (negative) prognostic marker for nasopharyngeal carcinoma patients (32). In HL, ID2 interacts with the retinoblastoma tumor suppressor protein to repress B-cell-specific gene expression via inactivation of E2A $(33,34)$. To the best of our knowledge, no study to date 
Table I. Immunohistochemistry and ISH results of $31 \mathrm{HL}$ cases.

\begin{tabular}{|c|c|c|c|c|c|}
\hline & $\begin{array}{l}\text { Histological } \\
\text { subtype }\end{array}$ & FoxO3a & ID1 & EBER-1 & LMP1 \\
\hline Case 1 & MCCHL & - & + & + & + \\
\hline Case 2 & MCCHL & - & + & + & + \\
\hline Case 3 & MCCHL & - & + & + & + \\
\hline Case 4 & MCCHL & + & - & - & - \\
\hline Case 5 & MCCHL & + & - & - & - \\
\hline Case 6 & MCCHL & + & - & - & - \\
\hline Case 7 & MCCHL & + & - & + & + \\
\hline Case 8 & MCCHL & + & - & + & + \\
\hline Case 9 & MCCHL & + & - & + & + \\
\hline Case 10 & MCCHL & + & + & - & - \\
\hline Case 11 & MCCHL & - & + & + & + \\
\hline Case 12 & MCCHL & - & + & + & + \\
\hline Case 13 & MCCHL & - & - & + & + \\
\hline Case 14 & MCCHL & - & - & + & + \\
\hline Case 15 & MCCHL & - & - & - & - \\
\hline Case 16 & NSCHL & + & - & - & - \\
\hline Case 17 & NSCHL & + & - & - & - \\
\hline Case 18 & NSCHL & + & - & - & - \\
\hline Case 19 & NSCHL & + & - & - & - \\
\hline Case 20 & NSCHL & + & - & - & - \\
\hline Case 21 & NSCHL & + & - & - & - \\
\hline Case 22 & NSCHL & + & - & - & - \\
\hline Case 23 & NSCHL & + & - & - & - \\
\hline Case 24 & NSCHL & + & - & - & - \\
\hline Case 25 & NSCHL & + & - & - & - \\
\hline Case 26 & NSCHL & + & - & - & - \\
\hline Case 27 & NSCHL & + & + & - & - \\
\hline Case 28 & NSCHL & - & + & + & + \\
\hline Case 29 & LRCHL & - & + & + & + \\
\hline Case 30 & NLPHL & - & + & - & - \\
\hline Case 31 & NLPHL & + & - & + & + \\
\hline
\end{tabular}

ISH, in situ hybridization; HL, Hodgkin's lymphoma; FoxO3a, Forkhead box O3a; ID1, inhibitor of DNA-binding protein-1; LMP1, latent membrane protein 1; EBER-1, Ebstein-Barr virus-encoded small RNA; MCCHL, mixed-cellularity classical HL; NSCHL, nodular sclerosis classical HL; LRCHL, lymphocyte-rich classical HL; NLPHL, nodular lymphocyte-predominant HL.

has investigated the role played by ID1 in HL. We herein addressed this issue, and found that one-third of HL patients (10 of 31) expressed ID1. No association was found between ID1 expression and histological HL subtype $(\mathrm{P}=0.21$, data not shown). ID1 and FoxO3a expressions were inversely correlated $(\mathrm{P}=0.00035)$. Birkenkamp et al reported that, in leukemia patients, ID1 transcription was negatively regulated by FoxO3a (24). This may also be the case in HL patients.

CIC detection is crucial for the development of novel, targeted cancer therapies. CICs may eliminate ROS (14). In previous studies, we observed that FoxO3a, a transcription
Table II. Correlation between FoxO3a and ID1 expression in HL cases.

\begin{tabular}{lrrr}
\hline & \multicolumn{2}{c}{ ID1 } & \\
\cline { 2 - 3 } Variable & $(-)$ & $(+)$ & P-value \\
\hline FoxO3a & & & \\
$(-)$ & 3 & 8 & 0.00035 \\
$(+)$ & 18 & 2 & \\
\hline
\end{tabular}

HL, Hodgkin's lymphoma; FoxO3a, Forkhead box O3a; ID1, inhibitor of DNA-binding protein-1.

Table III. Correlation among LMP1, ID1 and FoxO3a expression in HL cases.

\begin{tabular}{lrrrrrr}
\hline & \multicolumn{2}{c}{ ID1 } & & \multicolumn{2}{c}{ FoxO3a } & \\
\cline { 2 - 3 } Variable & $(-)$ & $(+)$ & P-value & $(-)$ & $(+)$ & P-value \\
\hline LMP1 & & & & & & \\
$(-)$ & 15 & 3 & 0.029 & 2 & 16 & 0.00085 \\
$(+)$ & 6 & 7 & & 9 & 4 & \\
\hline
\end{tabular}

HL, Hodgkin's lymphoma; FoxO3a, Forkhead box O3a; ID1, inhibitor of DNA-binding protein-1; LMP1, latent membrane protein 1.

factor upregulating genes encoding ROS-degrading enzymes, was abundantly expressed in the ROS-low regions of spreads of singly nucleated cells that resembled Hodgkin cells, but not in the RS cells of HL. Gold standard markers for HL are lacking, in contrast to the CD133 marker of brain and colon carcinomas and mantle cell lymphoma in animal models. Our results suggest that the FoxO3a-expressing cells may be the CICs of HL $(3,5,8,20-22,35)$. However, we found that several HL cases were negative for FoxO3a, and that the majority of FoxO3a-negative cases were EBV-positive (9 of 11). In nasopharyngeal carcinoma patients, EBV-encoded LMP1 inactivates FoxO3a (25-27). Similar to nasopharyngeal carcinoma, FoxO3a appeared to be degraded by LMP1 in HL tissue. The HL cell lines used in previous studies were EBV-negative, and populations of FoxO3a-positive cells were evident $(21,22)$. Therefore, FoxO3a may be a marker of the CICs of EBV-negative HL. The cells that eliminate ROS among the cells of EBV-positive HL remain to be identified. EBV-positive HL tissue expresses ID1 at high levels. Upon EBV infection, EBV-encoded LMP1 induces phosphorylation and inactivation of FoxO3a, which is associated with upregulation of ID1 (25-27). The ID proteins control various genes involved in tumor initiation and progression. For example, combined expression of ID1 and ID3 increased self-renewal and promoted tumor initiation by colon CICs via downregulation of p21 (31). Therefore, ID1 may be a useful marker of the CICs of EBV-positive HL.

Recent studies have demonstrated that aberrant levels of ID proteins are associated with the upregulation of pro-survival 
A
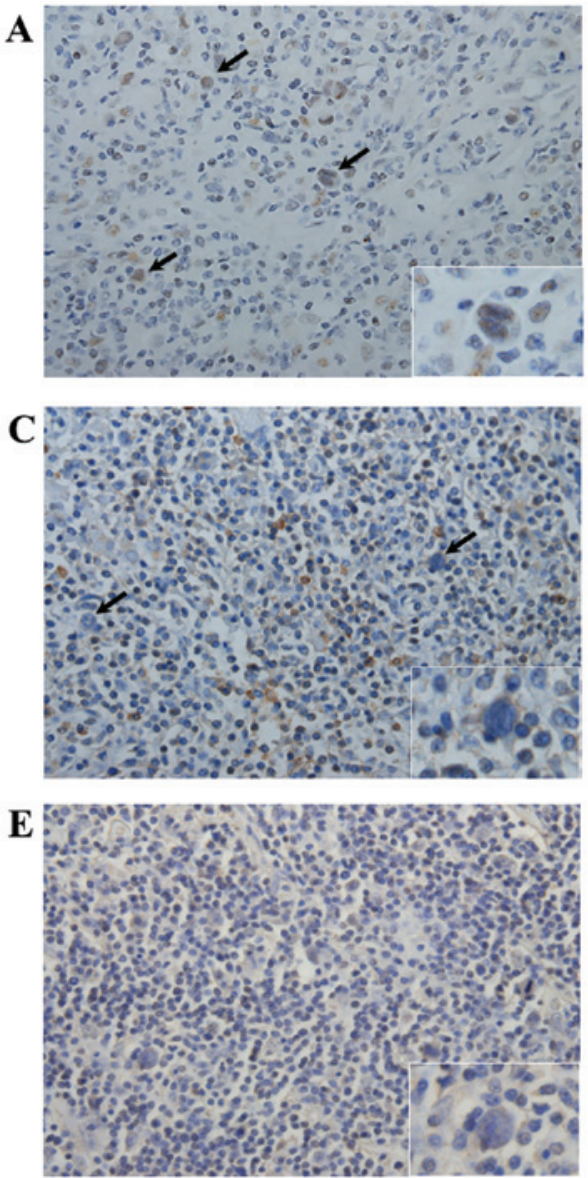

G

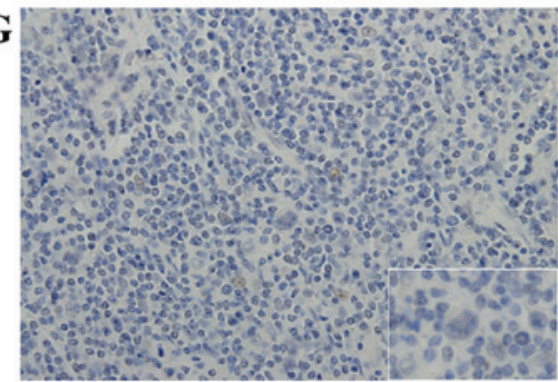

B

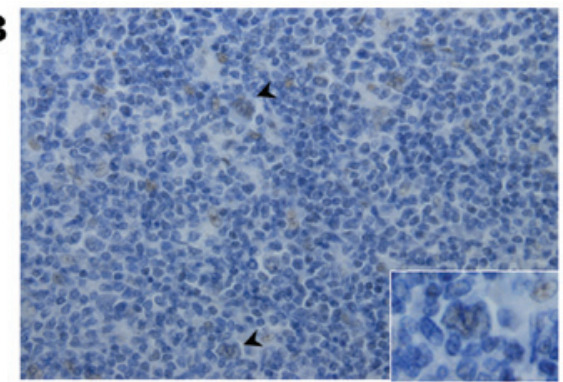

D
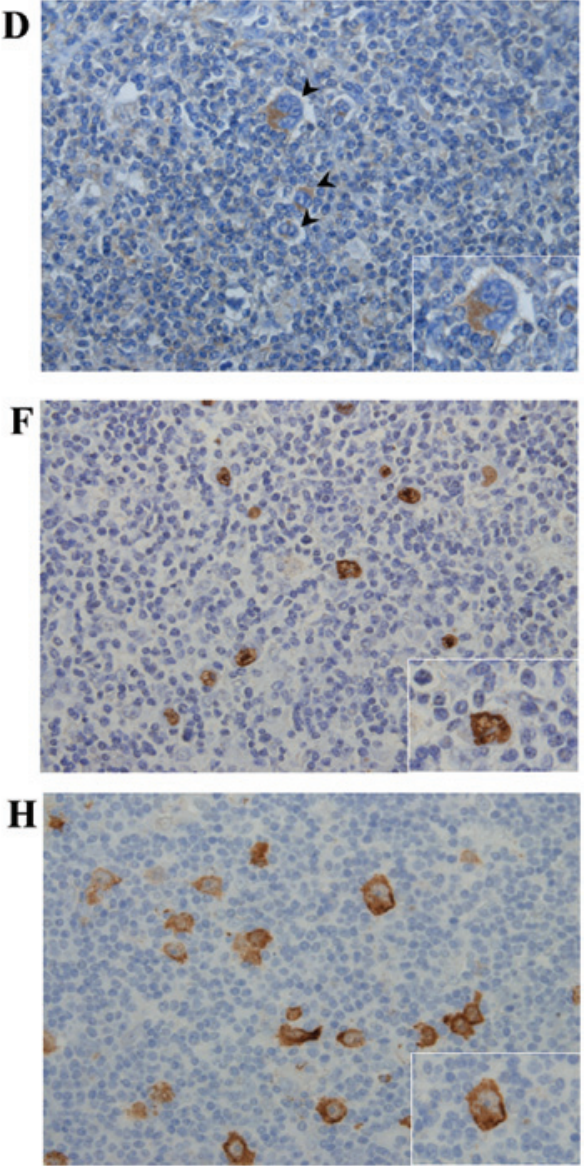

Figure 1. FoxO3a, ID1 and LMP1 expression in HL. Typical cases [case 4 (A, C, E and G) and case 1 (B, D, F and H)] are shown. (A-D) Immunohistochemical detection of FoxO3a (A and B) and ID1 (C and D). Positive FoxO3a staining was detected in a limited number of tumor cells in case 4 (A) arrows and inset; magnification, $\mathrm{x}$ 400. In case 1, tumor cells (B) arrowheads and inset did not stain at all for FoxO3a, but certain non-tumor cells, such as macrophages and vascular endothelial cells, stained positive for FoxO3a (magnification, x400). No ID1 signal was detected from tumor cells in case 4 (C) arrows and inset; magnification, $x 400$, whereas strong ID1 expression was evident in a limited number of tumor cells in case 1 (D) arrowheads and inset; magnification $x 400$. (E-H) EBER-1 in situ hybridization and immunohistochemical staining for the detection of LMP1. No EBER-1-positive/LMP1-expressing tumor cells were detected in case 4 (E and G), whereas tumor cells in case 1 stained positively for both EBER-1 and LMP1 (F and H). FoxO3a, Forkhead box O3a; ID1, inhibitor of DNA-binding protein 1; LMP1, latent membrane protein 1; EBER-1, Ebstein-Barr virus-encoded small RNA.

and anti-apoptotic factors, including nuclear factor- $\mathrm{\kappa B}(\mathrm{NF}-\mathrm{\kappa} \mathrm{B})$, B-cell lymphoma-2 and phosphoinositide 3-kinase-AKT, in several tumors $(23,32,36)$. Upon constitutive activation, NF- $\mathrm{kB}$ promotes proliferation and abrogates apoptosis of the Hodgkin and RS cells of HL $(37,38)$. Therefore, high-level ID1 expression in cases of EBV-positive HL may play an important role in the pathogenesis of the disease, via the action of NF- $\mathrm{kB}$. However, the correlation between NF- $\mathrm{kB}$ activation and EBV-infected conditions was controversial, and further studies are required (39).

In conclusion, the ID1 and FoxO3a expression levels in clinical samples from HL patients were found to be inversely correlated. LMP1 (EBV)-positive cases were usually FoxO3a-negative and ID1-positive. Our previous suggestion that FoxO3a may be a marker of CICs may not be applicable in cases of EBV-positive HL. Further studies are required to elucidate whether ID1-positive cells exhibit CIC-like characteristics.

\section{Acknowledgements}

The authors would like to thank Mr. Masaharu Kohara, Ms. Etsuko Maeno and Ms. Takako Sawamura for their valuable technical assistance. This study was supported by grants from the Ministry of Education, Culture, Sports, Science and Technology, Japan (nos. 25108507, 25460435, 15 H00894 and T264604700). 


\section{References}

1. Al-Hajj M, Wicha MS, Benito-Hernandez A, Morrison SJ and Clarke MF: Prospective identification of tumorigenic breast cancer cells. Proc Natl Acad Sci USA 100: 3983-3988, 2003.

2. Bonnet D and Dick JE: Human acute myeloid leukemia is organized as a hierarchy that originates from a primitive hematopoietic cell. Nat Med 3: 730-737, 1997.

3. Ikeda J, Tian T, Wang Y, Hori Y, Honma K, Wada N and Morii E: Expression of FoxO3a in clinical cases of malignant lymphoma. Pathol Res Pract 209: 716-720, 2013.

4. Matsui W, Wang Q, Barber JP, Brennan S, Smith BD, Borrello I, McNiece I, Lin L, Ambinder RF, Peacock C, et al: Clonogenic multiple myeloma progenitors, stem cell properties, and drug resistance. Cancer Res 68: 190-197, 2008.

5. O'Brien CA, Pollett A, Gallinger S and Dick JE: A human colon cancer cell capable of initiating tumor growth in immunodeficient mice. Nature 445: 106-110, 2007

6. Rahadiani N, Ikeda J, Mamat S, Matsuzaki S, Ueda Y, Umehara R, Tian T, Wang Y, Enomoto T, Kimura T, et al: Expression of aldehyde dehydrogenase 1 (ALDH1) in endometrioid adenocarcinoma and its clinical implications. Cancer Sci 102: 903-908, 2011.

7. Reya T, Morrison SJ, Clarke MF and Weissman IL: Stem cells, cancer, and cancer stem cells. Nature 414: 105-111, 2001.

8. Ricci-Vitiani L, Lombardi DG, Pilozzi E, Biffoni M, Todaro M, Peschle C and De Maria R: Identification and expansion of human colon-cancer-initiating cells. Nature 445: 111-115, 2007.

9. Singh SK, Hawkins C, Clarke ID, Squire JA, Bayani J, Hide T, Henkelman RM, Cusimano MD and Dirks PB: Identification of human brain tumour initiating cells. Nature 432: 396-401, 2004.

10. Sunayama J, Sato A, Matsuda K, Tachibana K, Watanabe E, Seino S, Suzuki K, Narita Y, Shibui S, Sakurada K, et al: FoxO3a functions as a key integrator of cellular signals that control glioblastoma stem-like cell differentiation and tumorigenicity. Stem Cells 29: 1327-1337, 2011.

11. Touil Y, Zuliani T, Wolowczuk I, Kuranda K, Prochazkova J, Andrieux J, Le Roy H, Mortier L, Vandomme J, Jouy N, et al: The PI3K/AKT signaling pathway controls the quiescence of the low-Rhodamine123-retention cell compartment enriched for melanoma stem cell activity. Stem Cells 31: 641-651, 2013.

12. Yin S, Li J, Hu C, Chen X, Yao M, Yan M, Jiang G, Ge C, Xie H, Wan D, et al: CD133 positive hepatocellular carcinoma cells possess high capacity for tumorigenicity. Int J Cancer 120 1444-1450, 2007.

13. Coffer PJ and Burgering BM: Stressed marrow: FoxOs stem tumour growth. Nat Cell Biol 9: 251-253, 2007.

14. Diehn M, Cho RW, Lobo NA, Kalisky T, Dorie MJ, Kulp AN, Qian D, Lam JS, Ailles LE, Wong M, et al: Association of reactive oxygen species levels and radioresistance in cancer stem cells. Nature 458: 780-783, 2009.

15. Santamaría CM, Chillón MC, García-Sanz R, Pérez C, Caballero MD, Ramos F, de Coca AG, Alonso JM, Giraldo P, Bernal T, et al: High FoxO3a expression is associated with a poorer prognosis in AML with normal cytogenetics. Leuk Res 33: 1706-1709, 2009

16. Tothova Z, Kollipara R, Huntly BJ, Lee BH, Castrillon DH, Cullen DE, McDowell EP, Lazo-Kallanian S, Williams IR, Sears C, et al: FoxOs are critical mediators of hematopoietic stem cell resistance to physiologic oxidative stress. Cell 128: 325-339, 2007.

17. Kanzler H, Küppers R, Hansmann ML and Rajewsky K: Hodgkin and Reed-Sternberg cells in Hodgkin's disease represent the outgrowth of a dominant tumor clone derived from (crippled) germinal center B cells. J Exp Med 184: 1495-1505, 1996.

18. Marofioti T, Hummel M, Foss HD, Laumen H, Korbjuhn P, Anagnostopoulos I, Lammert H, Demel G, Theil J, Wirth T and Stein H: Hodgkin and reed-sternberg cells represent an expansion of single clone originating from a germinal center B-cell with functional immunoglobulin gene rearrangements but defective immunoglobulin transcription. Blood 95: 1443-1450, 2000.

19. Jones RJ, Gocke CD, Kasamon YL, Miller CB, Perkins B Barber JP, Vala MS, Gerber JM, Gellert LL, Siedner M, et al: Circulating clonotypic B cells in classic Hodgkin lymphoma. Blood 113: 5920-5926, 2009.

20. Nakashima M, Ishii Y, Watanabe M, Togano T, Umezawa K, Higashihara M, Watanabe T and Horie R: The side population, as a precursor of Hodgkin and Reed-Sternberg cells and a target for nuclear factor- $\kappa \mathrm{B}$ inhibitors in Hodgkin's lymphoma. Cancer Sci 101: 2490-2496, 2010.
21. Ikeda J, Mamat S, Tian T, Wang Y, Luo W, Rahadiani N, Aozasa $\mathrm{K}$ and Morii E: Reactive oxygen species and aldehyde dehydrogenase activity in Hodgkin lymphoma cells. Lab Invest 92: 606-614, 2012.

22. Ikeda J, Mamat S, Tian T, Wang Y, Rahadiani N, Aozasa K and Morii E: Tumorigenic potential of mononucleated small cells of Hodgkin lymphoma cell lines. Am J Pathol 177: 3081-3088, 2010.

23. Lasorella A, Benezra R and Iavarone A: The ID proteins: Master regulators of cancer stem cells and tumour aggressiveness. Nat Rev Cancer 14: 77-91, 2014

24. Birkenkamp KU, Essafi A, van der Vos KE, da Costa M, Hui RC, Holstege F, Koenderman L, Lam EW and Coffer PJ: FoxO3a induces differentiation of Bcr-Abl-transformed cells through transcriptional down-regulation of Id1. J Biol Chem 282: 2211-2220, 2007.

25. Hau PM, Tsang CM, Yip YL, Huen MS and Tsao SW: Id1 interacts and stabilizes the Epstein-Barr virus latent membrane protein 1 (LMP1) in nasopharyngeal epithelial cells. PLoS One 6: e21176, 2011.

26. Li HM, Zhuang ZH, Wang Q, Pang JC, Wang XH, Wong HL, Feng HC, Jin DY, Ling MT, Wong YC, et al: Epstein-Barr virus latent membrane protein 1 (LMP1) upregulates Id1 expression in nasopharyngeal epithelial cells. Oncogene 23: 4488-4494, 2004.

27. Lo AK, Dawson CW, Lo KW, Yu Y and Young LS: Upregulation of Id1 by Epstein-Barr virus-encoded LMP1 confers resistance to TGFbeta-mediated growth inhibition. Mol Cancer 9: 155, 2010.

28. Gupta GP, Perk J, Acharyya S, de Candia P, Mittal V, Todorova-Manova K, Gerald WL, Brogi E, Benezra R and Massagué J: ID genes mediate tumor reinitiation during breast cancer lung metastasis. Proc Natl Acad Sci USA 104: 19506-19511, 2007.

29. Wada N, Ikeda J, Hori Y, Fujita S, Ogawa H, Soma T, Sugiyama H, Fukuhara S, Kanamaru A, Hino M, et al: Epstein-barr virus in diffuse large B-cell lymphoma in immunocompetent patients in Japan is as low as in Western Countries. J Med Virol 83: 317-321, 2011.

30. Hummel M, Anagnostopoulos I, Dallenbach F, Korbjuhn P, Dimmler $\mathrm{C}$ and Stein H: EBV infection patterns in Hodgkin's disease and normal lymphoid tissue: Expression and cellular localization of EBV gene products. Br J Haematol 82: 689-694, 1992.

31. O'Brien CA, Kreso A, Ryan P, Hermans KG, Gibson L, Wang Y, Tsatsanis A, Gallinger S and Dick JE: ID1 and ID3 regulate the self-renewal capacity of human colon cancer-initiating cells through p21. Cancer Cell 21: 777-792, 2012.

32. Sun W, Guo MM, Han P, Lin JZ, Liang FY, Tan GM, Li HB, Zeng $M$ and Huang XM: Id-1 and the p65 subunit of NF- $\kappa B$ promote migration of nasopharyngeal carcinoma cells and are correlated with poor prognosis. Carcinogenesis 33: 810-817, 2012.

33. Mathas S, Janz M, Hummel F, Hummel M, Wollert-Wulf B, Lusatis S, Anagnostopoulos I, Lietz A, Sigvardsson M, Jundt F, et al: Intrinsic inhibition of transcription factor E2A by HLH proteins ABF-1 and Id 2 mediates reprogramming of neoplastic B cells in Hodgkin lymphoma. Nat Immunol 7: 207-215, 2006.

34. Renné C, Martin-Subero JI, Eickernjäger M, Hansmann ML, Küppers R, Siebert R and Bräuninger A: Aberrant expression of ID2, a suppressor of B-cell-specific gene expression, in Hodgkin's lymphoma. Am J Pathol 169: 655-664, 2006.

35. Medina DJ, Abass-Shereef J, Walton K, Goodell L, Aviv H, Strair RK and Budak-Alpdogan T: Cobblestone-area forming cells derived from patients with mantle cell lymphoma are enriched for CD133+ tumor-initiating cells. PLoS One 9: e91042, 2014.

36. Ling MT, Wang X, Ouyang XS, Xu K, Tsao SW and Wong YC: Id-1 expression promotes cell survival through activation of NF-kappaB signalling pathway in prostate cancer cells. Oncogene 22: 4498-4508, 2003.

37. Hinz M, Lemke P, Anagnostopoulos I, Hacker C, Krappmann D, Mathas S, Dörken B, Zenke M, Stein H and Scheidereit C: Nuclear factor kappaB-dependent gene expression profiling of Hodgkin's disease tumor cells, pathogenetic significance, and link to constitutive signal transducer and activator of transcription 5a activity. J Exp Med 196: 605-617, 2002.

38. Hinz M, Löser P, Mathas S, Krappmann D, Dörken B and Scheidereit C: Constitutive NF-kappaB maintains high expression of a characteristic gene network, including CD40, CD86, and a set of antiapoptotic genes in Hodgkin/Reed-Sternberg cells. Blood 97: 2798-2807, 2001.

39. Küppers R: The biology of Hodgkin's lymphoma. Nat Rev Cancer 9: 15-27, 2009. 